\title{
In-process calibration of smart structures produced by incremental forming
}

\author{
Nassr Al-Baradoni ${ }^{1}\left[\right.$ Martin Krech $^{1} \cdot$ Peter Groche $^{1}$
}

Received: 23 July 2020 / Accepted: 11 November 2020 / Published online: 24 November 2020

(c) The Author(s) 2020

\begin{abstract}
Smart load-bearing structures are created by forming integration of functional materials into passive metallic components with target-oriented pre-stress conditions by rotary swaging. Their sensory capability cannot only be used during the utilization but also during the manufacturing phase. Previous works demonstrated how this capability paves the way for efficient monitoring and controlling of the used integration process. In search of an even higher overall efficiency of the manufacturing chain, the subsequent costly calibration step deserves closer attention. Therefore, a cost- and time-efficient approach for the process-integrated calibration of a sensor-integrated structure is proposed in this paper. During the in-process calibration, the acting process forces are measured both in the integrated sensor and in a special-built clamping fixture. The measured data can be transferred into calibration slopes of the sensory structures. A suitable signal processing based on the process characteristics is performed to compensate interference effects on the raw signals. As a result, an accuracy of the calibration better than $2 \%$ of the nominal value compared to an offline standardized calibration is achieved with the in-line calibration method. Consequently, efficiency in the manufacturing of sensory structures is further boosted by avoidance of setup or logistical operations.
\end{abstract}

Keywords Smart structures $\cdot$ Calibration of smart structures $\cdot$ Incremental forming $\cdot$ Joining by forming

\section{Motivation}

Today, load-bearing structures usually fulfill a purely mechanical function: transmit forces and torques safely to ensure reliable and trouble-free operation. To satisfy this requirement, these structures are traditionally dimensioned conservatively taking into account safety factors. However, this approach is expensive and an obstacle to lightweight designs. Within the scope of digitization, the demand for additional sensory or adaptive functions at low cost and high robustness is emerging. In order to meet this demand, many researchers are investigating a multitude of manufacturing technologies for multifunctional metallic structures with integrated functional materials.

In general, research in the production of smart structures using composite materials and hybrid structures is widely driven forward. For instance, the production of

Nassr Al-Baradoni

al-baradoni@ptu.tu-darmstadt.de

1 Technical University Darmstadt, Institute for Production Engineering and Forming Machines, Darmstadt, Germany polymer-based piezoelectric applications by additive manufacturing [1] or the integration of a piezo module by forming the initially powdery structural material layer by layer through a selective laser sintering process [2] have gained interest. The combination of a highly enriched thermoplastic polymer with piezo ceramic powder and thin metal sheets by combining extrusion and rolling [3] or the embedding of FBG sensors in civil engineering structures based on various technologies [4] are further examples of research work within this field. Other investigations center around the integration of piezoelectric transducers [5] and strain gauge-based sensors [6] into metallic structures by high pressure die casting, or around the integration of fiber optics on metallic structures by TIG welding [7].

Since most of these structures are produced by forming technologies, joining by forming has meanwhile established itself as a suitable technology for the integration of functional materials, such as transducers, into metallic load bearing structures. According to Groche et al., the joining process is based on the plastic deformation of at least one joining partner, which generates a force and/or form fit joint [8]. Groche et al., presented an integration processes, where 
piezo and strain gauge-based transducers are fixed and prestressed in metallic tubes [9] and fasteners [10] based on suitable process designs of the incremental forming processes recess and infeed [11] rotary swaging.

Schubert et al. introduce the integration of micro-piezo modules in micro-structured cavities within the surface of an aluminum sheet, prior to generating a force fit [12] and a form and force fit joint [13] by pressing.

Since joining by forming allows for target-oriented prestress conditions, the transducer to be integrated can also be used to monitor and even control the joining process. Müller et al. developed an in-process monitoring method for the preload evaluation and for fault detection during the integration of piezo modules into micro-structured aluminum sheets [14]. In order to obtain defined preload and therefore reproducible sensory properties of the sensory structures produced by incremental forming processes, Krech et al. use the signal of the force transducer that is to be integrated to control its preload during the integration process [15].

Once the integration process is accomplished, the created sensory structures are usually characterized in a downstream time-consuming calibration stage. A defined test sequence has to be performed on a testing machine according to standards, for example the standard ISO 376 for the static calibration of force sensors [16]. In addition to the static methods, there are also approaches for dynamic calibration methods, mainly applied to evaluate the dynamic behavior of the sensor. Recently, dynamic calibration methods are researched, in which forces are generated with the aid of accelerated masses. This allows to generate traceable, sinusoidal forces, which are used for a dynamic calibration of force sensors [17]. A further approach is to generate a defined impact [18] or step [19] excitation while recording the accelerations of the known masses and thus deriving the generated inertial forces. So far, a dynamic calibration must be followed by a static calibration, as otherwise a higher measurement uncertainty of more than $2 \%$ is to be expected [20]. According to the state of the art, both static as well as dynamic calibration methods are always conducted on stand-alone calibration machines, which necessitates considerable time and efforts for an additional process step.

Utilizing the transducer already during the integration of the sensor into the structure to control the joining process (see [15]) raises the question: which process conditions and signal processing allow for a process integrated calibration of sensory structures? A successful process integrated calibration of sensory structures could help to increase the economic efficiency of the manufacturing chain by avoiding the downstream calibration step. However, this approach requires both the suitability of the process used and a reliable determination of the resulting measurement uncertainty.

In this paper, we therefore investigate the integration of the calibration step into the manufacturing process of sensory structures produced by the incremental forming process rotary swaging. The aim of this work is the identification of new requirements resulting from the novel calibration approach. This includes the identification of appropriate time slots for the calibration, the determination of the limits with regard to accuracy and detectable component defects as well as the establishment of a suitable data processing method.

In detail, the paper is structured in the following way: In the next chapter, the process sequence for the integration and in-process calibration of produced sensory hollow structures is presented. Afterwards the experimental setup and the implemented data processing are described. In the fourth chapter, a comparison between standardized and inprocess calibration values is carried out. The results are then summarized and discussed.

\section{Process description}

Two aspects of incremental forming processes like rotary swaging are advantageous in terms of further integrating process steps in the production process of sensory structures. On the one hand, the forming tools only have a localized impact on the workpiece and generate stress states around the forming zone that are similar to those in the utilization phase. This allows for using the forces generated during the forming strokes as a calibration load. On the other hand, the loading and unloading of the tools offers the advantage of unambiguous zero points at various times. A possible zero offset during the integration process, e.g. as a result of a preload change, can be clearly identified. Moreover, the periodic dynamic load cycle consisting of loads and unloads is comparable to the load cycle for the periodic excitation of the dynamic calibrations [20]. The clamping fixture can furthermore be used as a convenient machineside reference point, since the occurring forces act both on the workpiece and on the clamping fixture along a unique path. Figure 1 illustrates the setup for the investigated inprocess calibration.

As can be seen in Fig. 1, the metallic tube with integrated force transducer is fixed in the clamping fixture. While the forming tools oscillate in radial direction during the forming process, the clamping fixture rotates and moves the tube out of the forming dies. This results in tensile forces $F_{\mathrm{ax}}$ along the path between the dies and the clamping. This force can be measured both by the integrated force transducer and by the sensors on the clamping surface.

The sensory structures investigated in this study consist of a strain gauge-based force transducer, which is joined into a metallic tube (Fig. 1). The form and force fit is generated through joining by plastic deformation of the metallic tube [8]. The manufacturing process used in this 
Fig. 1 Measurement setup for in-process calibration of sensory structures produced by rotary swaging. Acting axial process forces $\left(F_{a x}\right)$ are measured during the forming both in the tube $\left(F_{a x, t u b e}\right)$ and in the clamping $\left(F_{\text {ax,clamping }}\right)$

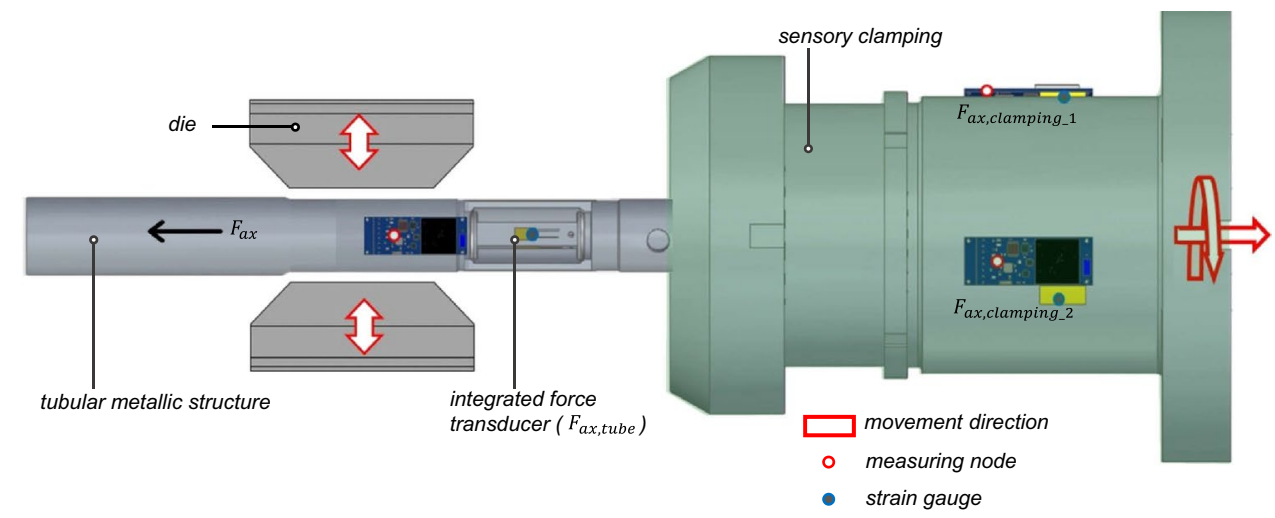

investigation is based on rotary swaging, which is an incremental forming process for changing the cross section of tubular or solid bar stock [21]. Four oscillating tools taper the workpiece by a large number of forming strokes while the workpiece rotates [22]. The outer diameter of the tube is reduced by hammering strokes and, as a result, the inside diameter decreases. After forming, the force transducer is joined with a preload inside the tube.

To achieve a form- and force-fit joint of the transducer, a four-step forming sequence is proposed: First, a preform is created with the aid of a mandrel (Fig. 2a), step I. At the subsequent insertion step, a force transducer is inserted into the preform and positioned at its end stop, step II. Both the previously used mandrel and the transducer have an inclined stop surface, so that there is a flat contact surface. The tube is clamped into the sensory clamping fixture and is further processed, step III. By this, the tube is deformed inwardly in the zone above and beyond the inlaid transducer. A mandrel from the opposing side is used to apply a pressure force $F_{\mathrm{m}}$ to keep the transducer in its position and to preload it during the joining. The material flows on the right shoulder of the integrated transducer, which generates an axial preload $F_{\mathrm{p}}$. During this process, the temperature of the tube $T_{\text {tube }}$ increases due to the plastic deformation while the transducer remains in a colder state. In step IV, the forming tools as well as the mandrel have moved away from the transducer zone. After some time, the temperatures of both components are at the same level again.

The transducer is preloaded by $F_{\mathrm{p}}$ during the integration process and can therefore be used to detect tensile forces acting on the tube. In [15] the effect of $F_{\mathrm{p}}$ on the sensory properties of the created sensory structure is thoroughly investigated. Due to the run-in angle of the tools and

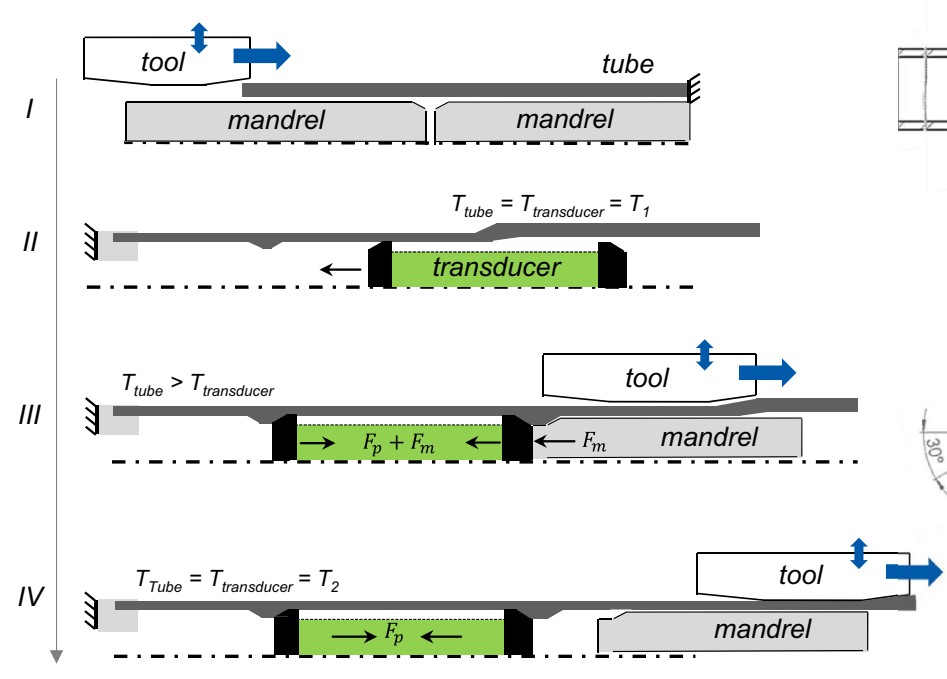

(a)

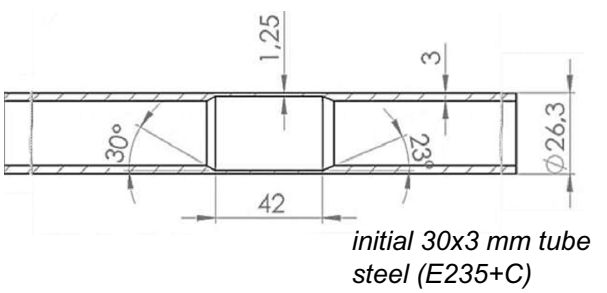

(b)

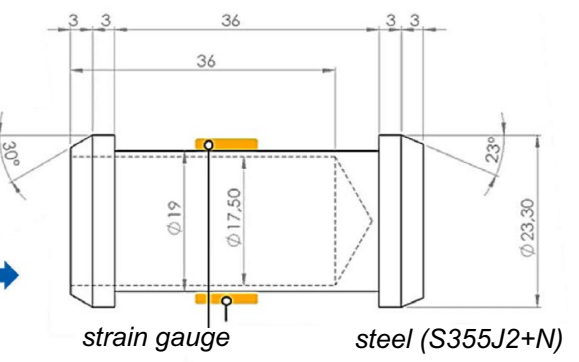

(c)

Fig. 2 Process design for the integration of force transducers into metallic hollow tubes by rotary swaging according to [23]. a Process stages, b the end geometry and the material of the sensory tube, $\mathbf{c}$ geometry and material of the integrated transducer 
the insertion, axial forces occur over the entire distance between the clamping fixture and the tool engagement. As soon as the tools are acting outside the joining zone, the axial forming forces can be measured by both, the newly created sensory tube and the sensory clamping fixture as a machine-side reference point (Fig. 1).

Figure 3 shows a measurement of an integration process (step II-step IV) by the integrated transducer in the tube and the sensory clamping fixture. At the beginning, a mandrel compression force $F_{\mathrm{m}}$ is applied, which is equally measured by the transducer and the sensory clamping fixture. As soon as the tools move out of the transducer's joining zone (from $22 \mathrm{~s}$ onwards), the mandrel is pulled out and tensile forming forces are equally acting both in the sensory tube and in the sensory clamping fixture.

It can be observed that the signals of the integrated sensor drift over the measuring time. The signals are affected by two significant interferences. One of them is the changing temperature at the transducer's joining zone caused by the different temperature levels inside the integrated transducer and the tube. The tube is heated due to forming and starts shrinking towards the cooler transducer. Hence, the zero-point line is shifted, which affects only the integrated transducer, but not the sensory clamping fixture. The signal of the transducer is drifting exponentially below the zero-line. The other significant interference is the sinusoidal zero-point drift of the signals. The axial force sensors are subject to a bending effect caused by the gravity on the structure (clamping and tube), which is increased as the tube comes into contact with the forming tools. The rotation of the structure results in a sinusoidal zero-point drift of the signals. These effects will be further analyzed in Sect. 3.2, when the data processing method is derived.

For the machine-side reference, the sensory clamping has to be designed in such a way that it is able to withstand high loads and to measure the loads with sufficient sensitivity at the same time. Additionally, the dynamic behavior of the structure has to be taken into account. In the following chapter, these central design features, the sensory clamping fixture and the procedure for data processing are described in detail.

\section{Test procedure}

\subsection{Sensory clamping fixture}

The clamping fixture has been identified as a suitable part for a unique machine-side measurement of the forming forces. The hollow clamping fixture is thus upgraded to a sensory clamping fixture by applying strain gauges and mounting measuring nodes on the outer surface (Fig. 1). To achieve high sensitivity, the wall thickness in the region of the strain gauges is reduced from 12 to $2 \mathrm{~mm}$. Two separate half bridges consisting of linear strain gauges are used to measure the axial forces. The two axial forces $F_{\text {ax,clamping_1 }}$ and $F_{\text {ax,clamping_ } 2}$ are averaged to a resulting force $F_{\text {ax,clamping. }}$. This increases the accuracy, which is a common measure for high-precision force transducers [24]. Due to the rotation of the clamping fixture during the forming process, signal

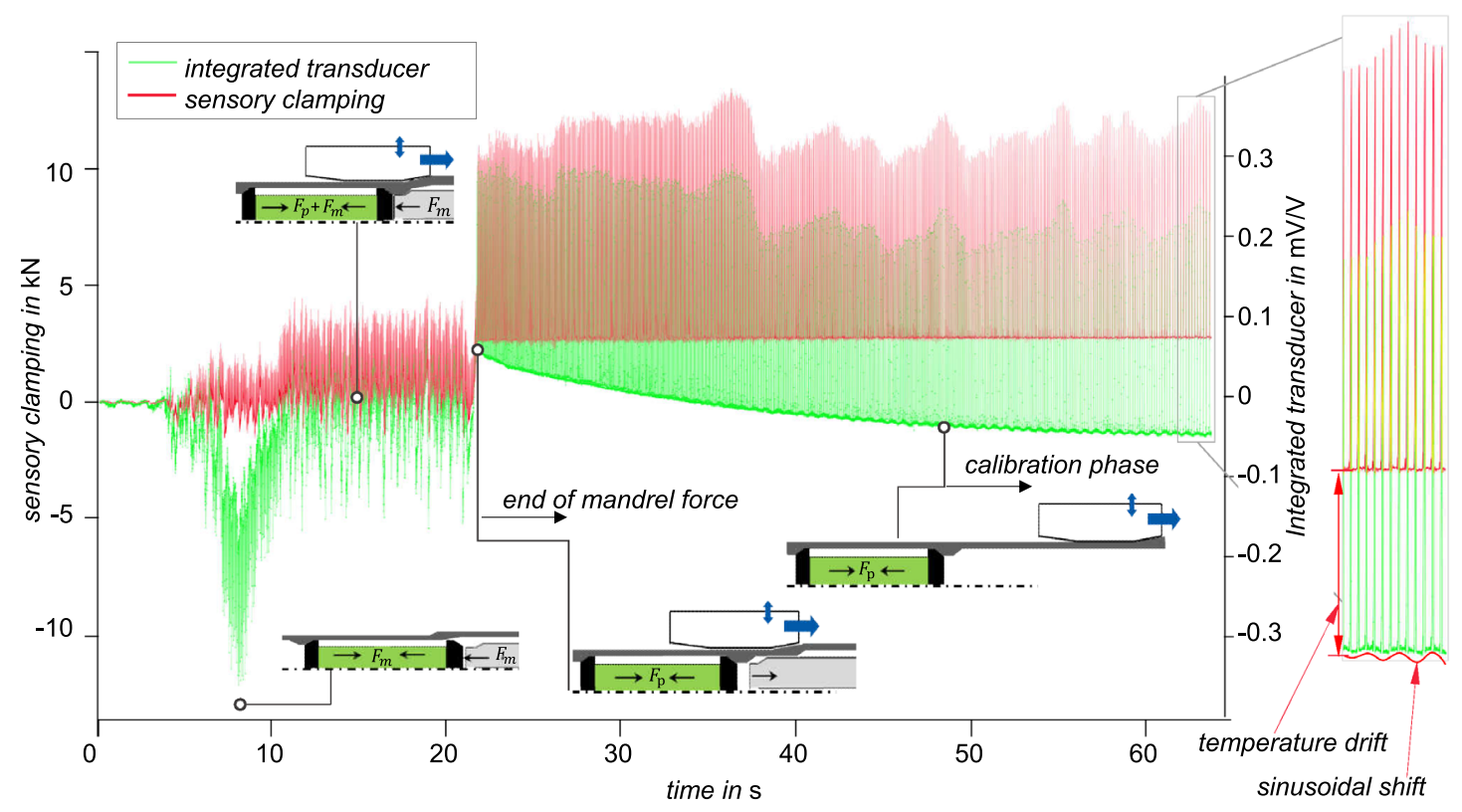

Fig. 3 Axial process forces at the integrated transducer and the sensory clamping fixture during the integration phase $(0 \mathrm{~s}$ to $22 \mathrm{~s})$ and the calibration phase ( $49 \mathrm{~s}$ to $65 \mathrm{~s}$ ) as well as the occurring zero-point drift 
amplifiers with wireless data transmission (wireless measuring nodes) "SG-Link ${ }^{\circledR}$-OEM-LXRS ${ }^{\circledR}$ " of the manufacturer "LORD Sensing" [25] are used.

The developed machine-side reference sensor itself is calibrated within the process-related force range $(0-12 \mathrm{kN})$ before use. A standardized static force calibration takes place in the mounting position and is carried out with the force sensor "KDM-30Z" of the manufacturer "me-systeme" according to the standard ISO 376 [16]. This results in a calibration value of $9.37 \mathrm{kN} /(\mathrm{mV} / \mathrm{V})$ for the first strain gauge sensor $F_{\text {ax,clamping_1 }}$ and $10.56 \mathrm{kN} /(\mathrm{mV} / \mathrm{V})$ for $F_{\text {ax,clamping_2 }}$. The end-value related deviation of the averaged signal $F_{\text {ax,clamping }}$ is 0.8 .

To investigate the dynamic behavior of the clamping device, the structure is first excited with an impact. Then it is also analyzed during the forming process at different stroke frequencies of the forming tools (Fig. 4). The standard oscillation frequency of $29 \mathrm{~Hz}$ (Fig. 4, top) and a reduced frequency of $2.5 \mathrm{~Hz}$ (Fig. 4, bottom) are used. To quantify the dynamic behavior, the spectral power density of the signals is analyzed.

It was found that both with a forming stroke frequency of $29 \mathrm{~Hz}$ as well as with impact excitation, characteristic oscillations in the range of approximately $1.8-2.3 \mathrm{kHz}$ occur in the force signals of the sensory clamping device. The detail view (Fig. 4, middle) of one forming stroke shows harmonics, which can only be found in the clamping signal, but not in the integrated transducer. With an oscillation frequency of the tools of $2.5 \mathrm{~Hz}$, no resonance of the clamping can be found. For the purpose of in-process calibration, the swaging frequency is reduced to $2-5 \mathrm{~Hz}$ as soon as the transducer is fully integrated in the tube (during step IV in Fig. 2 and at $t \approx 40 \mathrm{~s}$ in Fig. 3).

After establishing the most suitable time and swaging frequency for the calibration, six workpieces were produced and in-process calibrated according to the process and the part design in Fig. 2.

\subsection{Data processing}

To achieve an in-process calibration with acceptable measurement uncertainty, the process interferences must first be eliminated. The interferences mentioned in chapter two are neither constant nor reproducible. Once forming starts, the sinusoidal zero-point drift becomes greater due to the bending of the tube by the oscillating dies and more uneven due to the high forming torques that cause the workpiece to slip. In accordance to the height of the forming torques, the workpiece is allowed to slip off the clamping device due to the comparatively low clamping torque. In this way, high torsional stress in the tube can be avoided. Since neither the amplitude nor the angular frequency of the sinusoidal zeropoint drift can be reproduced, as the deformation behavior cannot be predicted exactly, it is necessary to develop

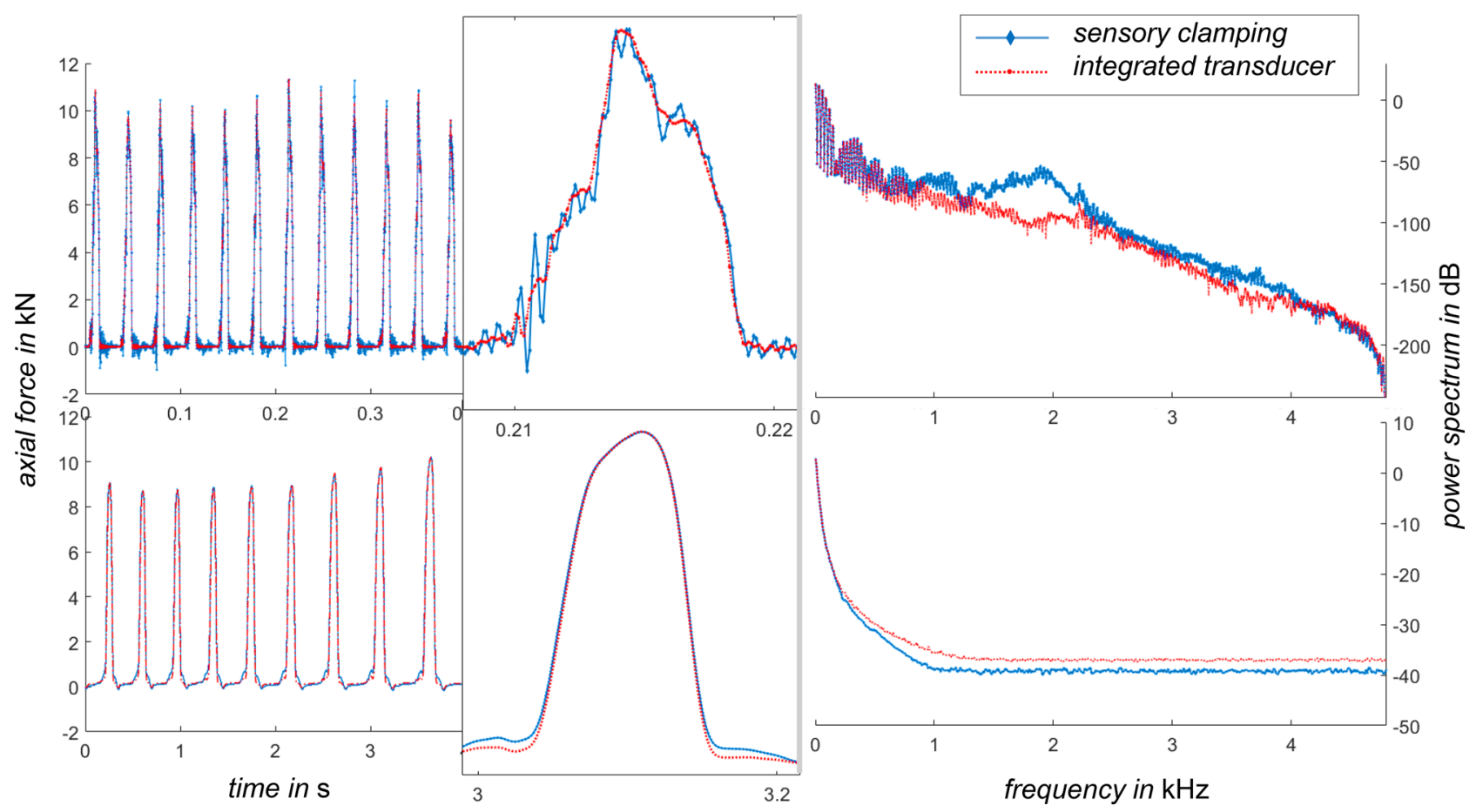

Fig. 4 Dynamic behavior of the measurement setup during the forming process at two different swaging frequencies. $29 \mathrm{~Hz}$ (top) and $2.5 \mathrm{~Hz}$ (bottom): Raw signals (left/middle) and spectral power density (right) 
suitable approaches for signal processing prior to calibration. The characteristic release state of the rotary swaging process, which occurs after each stroke, is used to correct the signals. The actual position of the zero-point in each signal is determined and then shifted to the expected position.

Firstly, the lower envelope in each raw signal is determined. Secondly the lower envelope is filtered by using a Gaussian smoothing filter to get a clear zero-point drift curve. Finally, the raw signal is corrected with the determined zero-point drift curve. Figure 5 demonstrates this procedure by correcting the sinusoidal zero-point drift.

Figure $5 \mathrm{a}, \mathrm{b}$ show, that the initial signal has almost a constant zero offset, as long as the clamping fixture does not rotate $(t<2 \mathrm{~s})$. Once the rotation starts $(t>2 \mathrm{~s})$, small sinusoidal zero shifts with relatively constant amplitude and angular frequency occur $(t<10 \mathrm{~s})$. This drift is caused by the gravitational force of the structure. When the deformation begins (at $t=10 \mathrm{~s}$ ), the amplitude of the sinusoidal drift becomes higher with non-uniform angular frequency, which can be observed clearly in Fig. 5b. As soon as the signals are corrected, a correct zero-point position can be observed (Fig. 5c). Due to the unique positions of the release states and the unidirectional loads, the zero-point drift caused by the temperature drift and the sinusoidal shift can be eliminated by this procedure. The force signals of the clamping fixture $F_{\text {ax, clamping_1 }}$ and $F_{\text {ax,clamping_2 }}$ are then averaged to one force signal in order to improve overall accuracy. The calibration value is then determined as the slope of the linear function determined by the regression of the point cloud (Fig. 6).
To determine the achievable accuracy of the in-process calibration, a recalibration according to the standard (ISO 376 [16]) was carried out for each of the six specimens on a tensile testing machine (Zwick Roell 100) with a tensile force of $12 \mathrm{kN}$. A comparison between the two types of the calibration shows a good correlation (Fig. 6) (right).

\section{Results}

In Table 1, the results are depicted with a comparison to the standardized calibration. For the in-process calibration, a time of $2 \mathrm{~s}$ within the calibration period is considered. The standard error is determined and used as an indicator for the scatter of the calibration value. A large standard deviation indicates a faulty sensory tube with a significant nonlinearity/hysteresis error, e.g. due to a badly applied strain gauge or an insufficiently preloaded transducer.

The calibration values lie within a range of $36.02 \mathrm{kN} /$ $(\mathrm{mV} / \mathrm{V})$ to $38.79 \mathrm{kN} /(\mathrm{mV} / \mathrm{V})$. The highest deviation between the in-process and the standardized calibration amounts only to $1.56 \%$ for part 3 . For both calibration methods, the standard deviation in relation to the nominal value is calculated as well. Part number 6 represents an outlier, as a large deviation in the standard deviation occurs. For this reason, no calibration value is determined. A look at the raw signals reveals clear deviations and a hysteresis during in-process calibration as well as during the standardized calibration on the testing machine (Fig. 7).

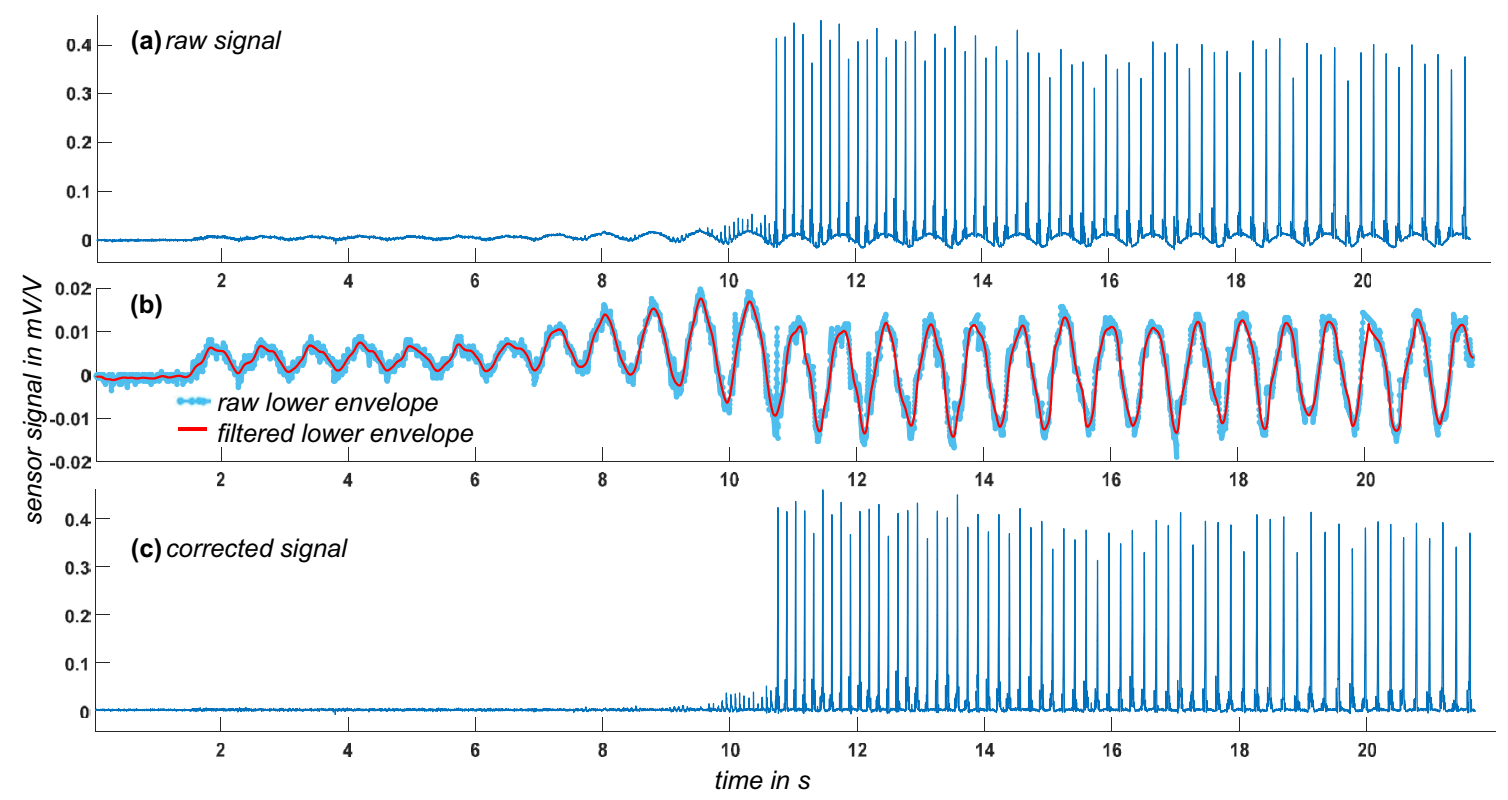

Fig. 5 Signal processing and correction: a raw signal, $\mathbf{b}$ the lower envelope and the filtered lower envelope, (c) force signal after correction the zero-point drift 

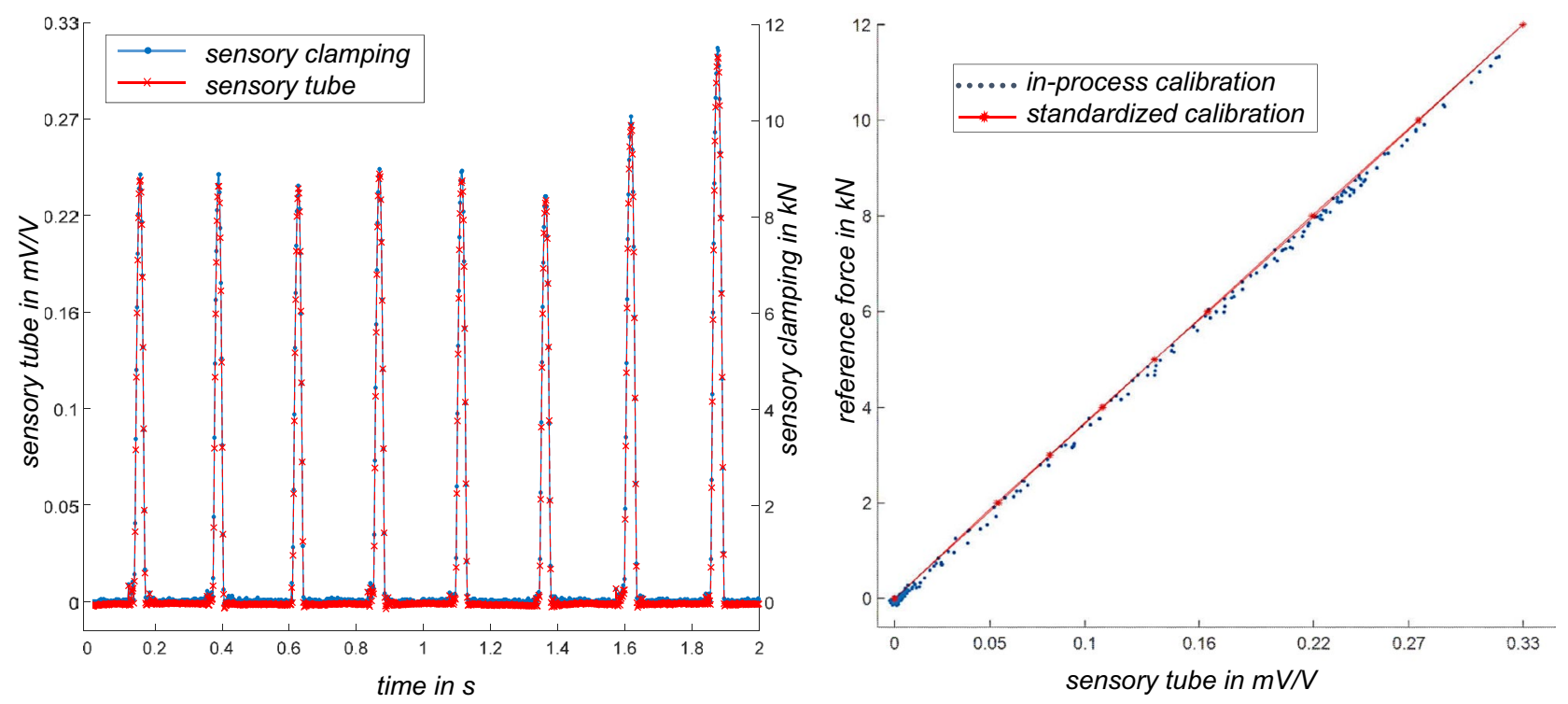

Fig. 6 Resulting axial force curve and point cloud of part 4 (left), resulting point cloud and comparison with standardized calibration (right) to a standardized calibration
Table 1 Results of the in-process calibration compared

\begin{tabular}{llllll}
\hline Part & $\begin{array}{l}\text { In-process calibration } \\
\text { value in kN/(mV/V) }\end{array}$ & $\begin{array}{l}\text { Std dev./nom. } \\
\text { value in } \%\end{array}$ & $\begin{array}{l}\text { Standardized calibra- } \\
\text { tion value in kN/ } \\
\text { (mV/V) }\end{array}$ & $\begin{array}{l}\text { Std dev./nom. } \\
\text { value in } \%\end{array}$ & $\begin{array}{l}\text { Dev. in-process/ } \\
\text { standardized in \% }\end{array}$ \\
\hline 1 & 36.19 & 0.33 & 36.51 & 0.08 & 0.87 \\
2 & 36.02 & 0.36 & 36.30 & 0.15 & 0.75 \\
3 & 37.87 & 0.63 & 37.29 & 0.1 & 1.56 \\
4 & 38.05 & 0.4 & 37.81 & 0.2 & 0.63 \\
5 & 38.79 & 0.5 & 38.56 & 0.3 & 0.59 \\
6 & - & 1.6 & - & 0.7 & - \\
\hline
\end{tabular}
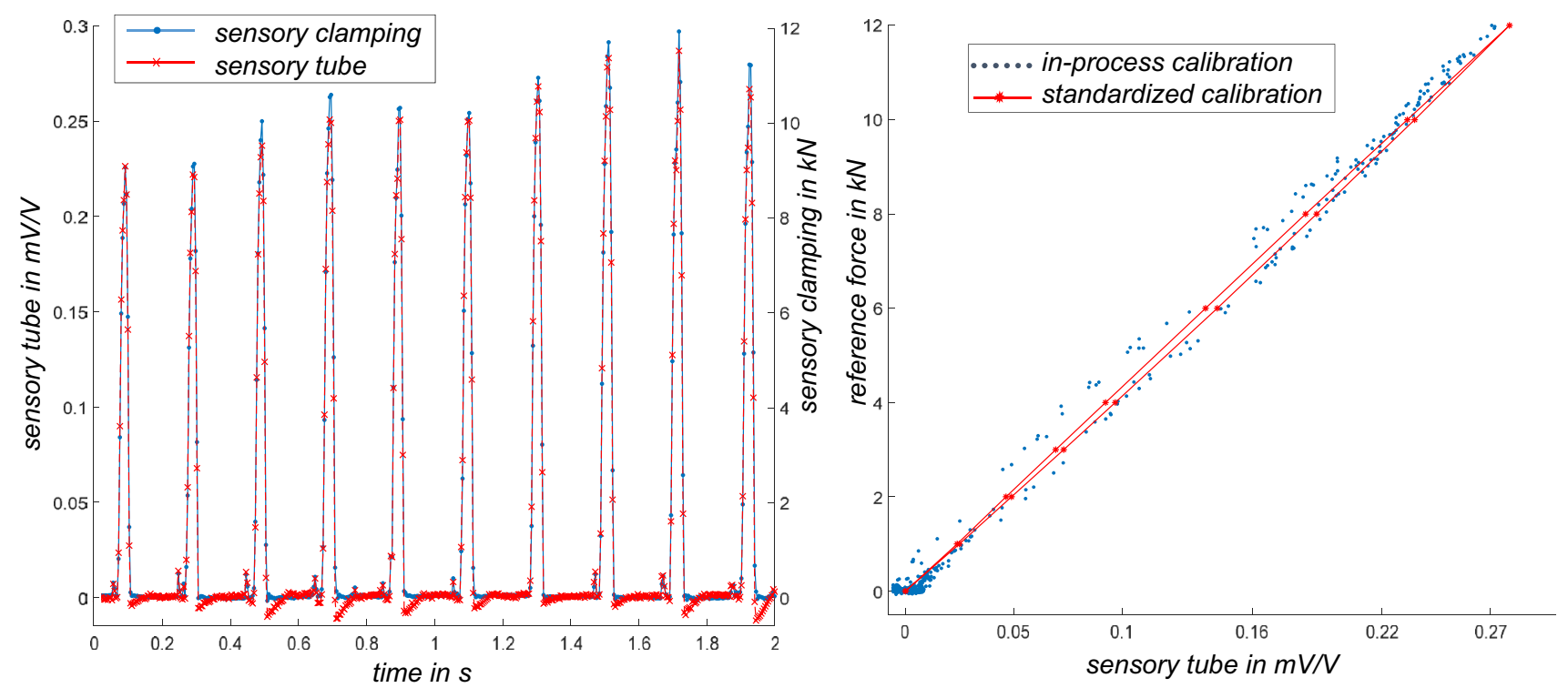

Fig. 7 Resulting axial force curve and point cloud of the faulty part 6 (left), resulting point cloud and comparison with standardized calibration 
This demonstrates the complementary possibility to detect faulty sensors by analyzing the standard deviation of the regression line. In this example, the preload $F_{\mathrm{p}}$ generated by the preceding joining process was too low. As can be seen, a clear hysteresis occurs both during inprocess calibration and during standardized calibration. All other specimens show a distinct linear behavior similar to Fig. 6.

\section{Conclusion}

This paper presents a novel calibration method applicable to sensory structures produced by incremental forming. During the manufacturing process, an axial force transducer is integrated into a metallic structure using a rotary swaging process. At the same time, the created sensory structure is calibrated with the help of the occurring process forces, which are measured by the created sensory structure and the machine-side reference sensor. For this, a sensory clamping fixture is designed and optimized regarding its sensitivity. Then the swaging frequency of the machine is reduced to avoid any resonance behavior in the clamping. Due to the oscillating tool impacts during rotary swaging, the force curves always have clear zero positions after each hammer stroke. This allows suitable signal processing to eliminate process-related side effects such as thermal drift or sinusoidal zero-point drift due to bending moments.

A comparison with a subsequent standardized calibration on a tensile testing machine shows that the in-process calibration leads to a deviation of $\max 1.5 \%$. Consequently, a measurement uncertainty for in-process calibrated sensory structures of max. $2 \%$ can be assumed, which is in accordance with stand-alone dynamic calibrations based on periodic excitation. As a result, sensory structures can be calibrated during manufacture without extending the process chain by a subsequent calibration procedure. Faulty parts can already be detected during the forming process by evaluating the standard deviation of the calculated regression.

The work described reveals that the necessary effort for the production of sensory structures can be drastically reduced if downstream processes like calibration or quality control are integrated into the manufacturing process itself. Incremental forming processes appear to be particularly suitable for this kind of integration, because their processinherent properties of multiple loading and unloading and the low forming forces facilitate the use of process signals to determine product properties. This utilization can only be successful if the mechanical and thermal conditions and behavior of the entire manufacturing system are thoroughly taken into account.
Acknowledgements This research is funded by the Deutsche Forschungsgemeinschaft (DFG, German Research Foundation)-Projektnummer 57157498-SFB 805. The authors would like to thank the German Research Foundation for founding and supporting this research project within the CRC 805 .

Funding Open Access funding enabled and organized by Projekt DEAL.

Open Access This article is licensed under a Creative Commons Attribution 4.0 International License, which permits use, sharing, adaptation, distribution and reproduction in any medium or format, as long as you give appropriate credit to the original author(s) and the source, provide a link to the Creative Commons licence, and indicate if changes were made. The images or other third party material in this article are included in the article's Creative Commons licence, unless indicated otherwise in a credit line to the material. If material is not included in the article's Creative Commons licence and your intended use is not permitted by statutory regulation or exceeds the permitted use, you will need to obtain permission directly from the copyright holder. To view a copy of this licence, visit http://creativecommons.org/licenses/by/4.0/.

\section{References}

1. Lee C, Tarbutton JA (2014) Electric poling-assisted additive manufacturing process for PVDF polymer-based piezoelectric device applications. Smart Mater Struct. https://doi. org/10.1088/0964-1726/23/9/095044

2. Stoffregen H, Fischer J, Flaschenträger D, Rauschenbach M, Nuffer J, Melz T et al (2011) Additive manufacturing of adaptive components by selective laser melting. Adaptronic Congress, Darmstadt, pp 82-89

3. Kräusel V, Graf A, Heinrich M, Decker R, Caspar M, Kroll L et al (2015) Development of hybrid assembled composites with sensory function. CIRP Ann Manuf Technol. https://doi. org/10.1016/j.cirp.2015.04.054

4. Majumder M, Gangopadhyay TK, Chakraborty AK, Dasgupta K, Bhattacharya DK (2008) Fibre Bragg gratings in structural health monitoring-present status and applications. Sens Actuators A. https://doi.org/10.1016/j.sna.2008.04.008

5. Schwankl M, Rübner M, Singer RF, Körner C (2013) Integration of PZT-ceramic modules using hybrid structures in high pressure die casting. Procedia Mater Sci. https://doi.org/10.1016/j. mspro.2013.02.020

6. Tiedemann R, Pille C, Dumstorff G, Lang W (2017) Sensor integration in castings made of Aluminum-new approaches for direct sensor integration in aluminum high pressure die casting. Key Eng Mater. https://doi.org/10.4028/www.scientific.net/ KEM.742.786

7. Grandal T, Fraga S, Vazquez JA, Zornoza A (2016) Technique for embedding fiber optics in metallic structures for smart material applications. 8th European workshop on structural health monitoring (EWSHM 2016), pp 5-8

8. Groche P, Wohletz S, Brenneis M, Pabst C, Resch F (2014) Joining by forming-a review on joint mechanisms, applications and future trends. J Mater Process Technol. https://doi. org/10.1016/j.jmatprotec.2013.12.022

9. Groche P, Türk M (2011) Smart structures assembly through incremental forming. CIRP Ann Manuf Technol. https://doi. org/10.1016/j.cirp.2011.03.003

10. Groche P, Brenneis M (2014) Manufacturing and use of novel sensoric fasteners for monitoring forming processes. Measur 
J Int Measur Confed. https://doi.org/10.1016/j.measuremen t.2014.03.042

11. Groche P, Krech M (2017) Efficient production of sensory machine elements by a two-stage rotary swaging process-relevant phenomena and numerical modelling. J Mater Process Technol. https://doi.org/10.1016/j.jmatprotec.2016.11.034

12. Schubert A, Wittstock V, Koriath HJ, Jahn SF, Peter S, Müller B et al (2014) Smart metal sheets by direct functional integration of piezoceramic fibers in microformed structures. Microsyst Technol. https://doi.org/10.1007/s00542-013-1836-6

13. Schubert A, Wittstock V, Jahn SF, Müller B, Müller M (2014) Joining by forming of piezoceramic macro-fiber arrays within micro-structured surfaces of aluminum sheets. Prod Eng Res Devel. https://doi.org/10.1007/s11740-013-0498-7

14. Müller B, Pierer A, Schmidt M, Schubert A, Koriath HJ, Putz $M$ et al (2017) In-process monitoring of joining operations for piezoceramic elements. Key Eng Mater. https://doi.org/10.4028/ www.scientific.net/kem.742.800

15. Krech M, Trunk A, Groche P (2018) Controlling the sensor properties of smart structures produced by metal forming. J Mater Process Technol. https://doi.org/10.1016/j.jmatprotec .2018 .07 .014

16. ISO 376:2011 (2011) Metallic materials-calibration of force proving instruments used for the verification of uniaxial testing machines

17. Kobusch M, Eichstädt S (2017) A case study in model-based dynamic calibration of small strain gauge force transducers. ACTA IMEKO. https://doi.org/10.21014/acta_imeko.v6i1.433

18. Bartoli C, Beug MF, Bruns T, Elster C, Esward T, Klaus L et al (2013) Traceable dynamic measurement of mechanical quantities: objectives and first results of this European project. Int J Metrol Qual Eng. https://doi.org/10.1051/ijmqe/2012020
19. Fujii Y (2006) Dynamic calibration methods for force transducers. In: XVIII IMEKO world congress: Metrology for a Sustainable Development, pp 17-22

20. Bruns T, Eichstädt S, Gaube T, Gerber S, Häuser C, Iwanczik $M$ et al (2017) Dynamic calibration of uniaxial force measuring devices and testing machines (basic principles). https://doi. org/10.7795/550.20171212A

21. Groche P, Fritsche D, Tekkaya EA, Allwood JM, Hirt G, Neugebauer R (2007) Incremental bulk metal forming. CIRP Ann Manuf Technol. https://doi.org/10.1016/j.cirp.2007.10.006

22. Uhlig A (1963) Investigation of the movements and forces in rotary swaging. Untersuchung über die Bewegungen und Kräfte beim Rundkneten, Uhlig A, TH-Hannover [Ph.D. Thesis]

23. Krech M (2020) Adaptive forming process for the production and simultaneous calibration of metallic structures with componentintegrated force and torque sensors. Adaptiver Umformprozess zur Herstellung und simultanen Kalibrierung von metallischen Strukturen mit bauteilintegrierten Kraft- und Drehmomentsensoren, Düren, Shaker Verlag, TU Darmstadt, ISBN 978-3-84407514-4 [Ph.D. Thesis]

24. Ştefănescu DM (2011) Handbook of force transducers. Handb Force Transducers. https://doi.org/10.1007/978-3-642-18296-9

25. LORD MicroStrain (2020). https://www.microstrain.com/wirel ess/sg-link-oem-lxrs

Publisher's Note Springer Nature remains neutral with regard to jurisdictional claims in published maps and institutional affiliations. 